\title{
Damage Control for renal trauma: the more conservative the surgeon, better for the kidney
}

\section{Control de daños renal: entr e más conservador sea el cirujano mejor para el riñón}

\author{
Alexander Salcedo ${ }^{1,2,3,4}$ Carlos A. Ordoñez ${ }^{1,2,3}$ Michael W. Parra $^{5}{ }^{(D)}$ José Daniel Osorio $^{6}$ \\ Mónica Guzmán-Rodríguez ${ }^{{ }^{(D)}}$ Luis Fernando Pino ${ }^{2,4}$ Mario Alain Herrera ${ }^{2,4}{ }^{(D)}$ Adolfo \\ González Hadad $^{2,4,8}$ José Julián Serna ${ }^{1,2,3,4}$ Alberto García $^{1,2,3}$ Federico Coccolini $^{(\mathbb{D}}$ \\ Fausto Catena ${ }^{10}$ (D)
}

ordonezcarlosa@gmail.com, carlos.ordonez@fvl.org.co

1. Fundación Valle del Lili, Department of Surgery, Division of Trauma and Acute Care Surgery, Cali, Colombia. 2. Universidad del Valle, Facultad de Salud, Escuela de Medicina, Department of Surgery, Division of Trauma and Acute Care Surgery, Cali, Colombia 3 Universidad Icesi, Cali, Colombia. 4 Hospital Universitario del Valle Division of Trauma and Acute Care Surgery, Department of Surgery, Cali, Colombia. 5 Broward General Level I Trauma Center, Department of Trauma Critical Care, Fort Lauderdale, FL, USA, 6 Universidad del Valle, Facultad de Salud, Department of Surgery, Cali, Colombia Cali, Colombia, 7 Universidad de Chile, Facultad de Medicina, Instituto de Ciencias Biomédicas, Santiago de Chile, Chile., 8 Centro Médico Imbanaco, Cali, Colombia. 9 Pisa University Hospital, Department of General, Emergency and Trauma Surgery, Pisa, Italy, 10 Parma Maggiore Hospital, Department of Emergency Surgery, Parma, Italy.,

\section{Abstract}

Urologic trauma is frequently reported in patients with penetrating trauma. Currently, the computerized tomography and vascular approach through angiography/embolization are the standard approaches for renal trauma. However, the management of renal or urinary tract trauma in a patient with hemodynamic instability and criteria for emergency laparotomy, is a topic of discussion. This article presents the consensus of the Trauma and Emergency Surgery Group (CTE) from Cali, for the management of penetrating renal and urinary tract trauma through damage control surgery. Intrasurgical perirenal hematoma characteristics, such as if it is expanding or actively bleeding, can be reference for deciding whether a conservative approach with subsequent radiological studies is possible. However, if there is evidence of severe kidney trauma, surgical exploration is mandatory and entails a high probability of requiring a nephrectomy. Urinary tract damage control should be conservative and deferred, because this type of trauma does not represent a risk in acute trauma management.

Copyright: @ 2021 Universidad del Valle (c) (1) 8 


\section{Conflicts of interest:}

The authors declare that they have no conflict of interest.

\section{Acknowledgments:}

We would like to extend our gratitude to the anatomical illustrator Fabian R. Cabrera P., Professor of the Design Department of the Integrated Arts Faculty, for the illustrations and cover design. Philip Leib, Yaset Caicedo and Natalia Padilla for their comments on the drafting of the manuscript.

\section{Corresponding author:}

Carlos A. Ordonez, MD, FACS. Division of Trauma and Acute Care Surgery, Department of Surgery. Fundación Valle del Lili. Cali, Colombia; Division of Trauma and Acute Care Surgery, Department of Surgery, Universidad del Valle, Cali, Colombia; Universidad Icesi, Cali, Colombia. e-mail: ordonezcarlosa@gmail.com, carlos.ordonez@fvl.org.co

\section{Resumen}

El trauma renal y de las vías urinarias se presenta con relativa frecuencia en pacientes con trauma penetrante. El estándar actual de manejo es realizar una evaluación imagenológica, por medio de tomografía computarizada y un abordaje vascular, a través de técnicas de angiografía/embolización. Sin embargo, el manejo de un paciente hemodinámicamente inestable con criterios de laparotomía de emergencia, con hallazgos de trauma renal o de vías urinarias es aún tema de discusión. El siguiente articulo presenta el consenso del grupo de Cirugía de Trauma y Emergencias (CTE) de Cali respecto al manejo del trauma penetrante renal y de vías urinarias mediante cirugía de control de daños. Las características intra quirúrgicas del hematoma perirrenal tales como si es expansivo o si tiene signos de sangrado activo, son puntos de referencia para decidir entre un abordaje conservador, por estudios imagenológicos posteriores. En cambio, si existe la sospecha de un trauma renal severo, se debe realizar exploración quirúrgica con alta probabilidad de una nefrectomía. El manejo de control de daños de las vías urinarias debe ser conservador y diferido, la lesión de estos órganos no representa un riesgo en el manejo agudo del trauma.

\section{Remark}

\section{1) Why was this study conducted?}

This article presents the consensus the management of penetrating renal and urinary tract trauma through damage control surgery.

\section{2) What were the most relevant results of the study?}

Intrasurgical perirenal hematoma characteristics, such as if it is expanding or actively bleeding, can be reference for deciding whether a conservative approach with subsequent radiological studies is possible. However, if there is evidence of severe kidney trauma, surgical exploration is mandatory and entails a high probability of requiring a nephrectomy.

\section{3) What do these results contribute?}

Urinary tract damage control should be conservative and deferred because this type of trauma does not represent a risk in acute trauma management. 


\section{Introduction}

Urologic trauma has a low prevalence and the most commonly injured organ is the kidney ${ }^{1}$. In $80 \%$ of the cases, kidney injuries are due to blunt trauma. Great changes in diagnosis and management of renal trauma have been made due to advances in diagnostic imaging and non-operative management ${ }^{2}$. Currently, endovascular techniques and angioembolization are considered the cornerstones in blunt renal trauma management and have decreased the use of more invasive techniques such as total nephrectomy ${ }^{3}$.

Nevertheless, the management of patients with penetrating renal trauma and hemodynamic instability requires emergency surgical exploration without allowing a prior radiological evaluation. On the other hand, ureters, bladder and other urologic organs are less frequently injured ${ }^{4}$ and have a low risk of developing hemodynamic instability ${ }^{1,2,5,6}$.

This article is a consensus that synthesizes the experience earned during the past 30 years in trauma critical care management of the severely injured patient from the Trauma and Emergency Surgery Group (CTE) from Cali, Colombia. This consensus was built by experts from the University Hospital Fundación Valle del Lili, the university Hospital del Valle "Evaristo Garcia", the Universidad del Valle and Universidad Icesi, the Asociacion Colombiana de Cirugia, the Pan-american Trauma Society, and with the collaboration of national and international specialists of the United States of America and Europe. This article aims to describe a decision-making algorithm for the management of urologic trauma in patients with hemodynamic instability that undergo Damage Control Surgery.

\section{Epidemiology}

Genitourinary tract injuries can be identified in $8-10 \%$ of the patients with abdominal blunt trauma and in about $6 \%$ of penetrating trauma patients ${ }^{6,7}$. The most commonly injured organ is the kidney, being found in $65 \%$ of the patients with urologic trauma ${ }^{3}$. Renal trauma accounts for $1-5 \%$ of all the admissions to the emergency department $[2,8]$. This type of trauma is frequently associated with lesions in another organs, mainly in abdominal trauma, in which the liver (37\%) and the spleen $(29 \%)$ are the most commonly injured organs ${ }^{8-10}$. Even though most of the cases of renal trauma are blunt trauma, urban violence has increased the incidence of penetrating renal trauma ${ }^{11}$. This was shown in a study conducted by Mingoli et al., that described 13,824 renal trauma patients, of which, 10,826 (78.3\%) had penetrating trauma and 2,998 (21.7\%) had blunt trauma. Eighty one percent had high-grade renal trauma and $18.5 \%$ had low-grade trauma. Eighty two percent underwent non-surgical management and $17.3 \%$ required surgery. Surgical management was more frequent in patients with highgrade injury and penetrating trauma ${ }^{12}$.

Ureteral injuries account for 1 to $5 \%$ of urinary tract injuries ${ }^{9,13}$. The most frequent injury mechanism is penetrating trauma and the most frequently injured anatomical portion is the distal third of the ureter ${ }^{6,14}$. Bladder trauma accounts for about $12 \%$ of urinary tract injuries ${ }^{9}$. 65 to $86 \%$ of bladder trauma cases are of blunt mechanism. This type of injury is associated with pelvic fracture in 60 to $90 \%$ of the cases. However, patients admitted with pelvic fractures have a low rate of bladder injury $(6-8 \%)^{7,15,16 .}$

\section{Initial assessment and diagnosis}

Initial management must be directed towards the hemodynamic stabilization of the patient according to the Advanced Trauma Life Support (ATLS) guidelines ${ }^{17,18}$. Clinical signs that suggest urinary tract injury are lumbar hematoma or ecchymosis, hematuria, and rib fractures ${ }^{1,5,15}$. The use of e-FAST or another ultrasound technique have low sensitivity, meaning that a negative result does not rule out the diagnosis ${ }^{19-23}$. If the patient is hemodynamically stable or is transiently stabilized, a double-contrasted Computed Tomography (CT) should be 
Table 1. AAST classification of kidney injuries ${ }^{26}$

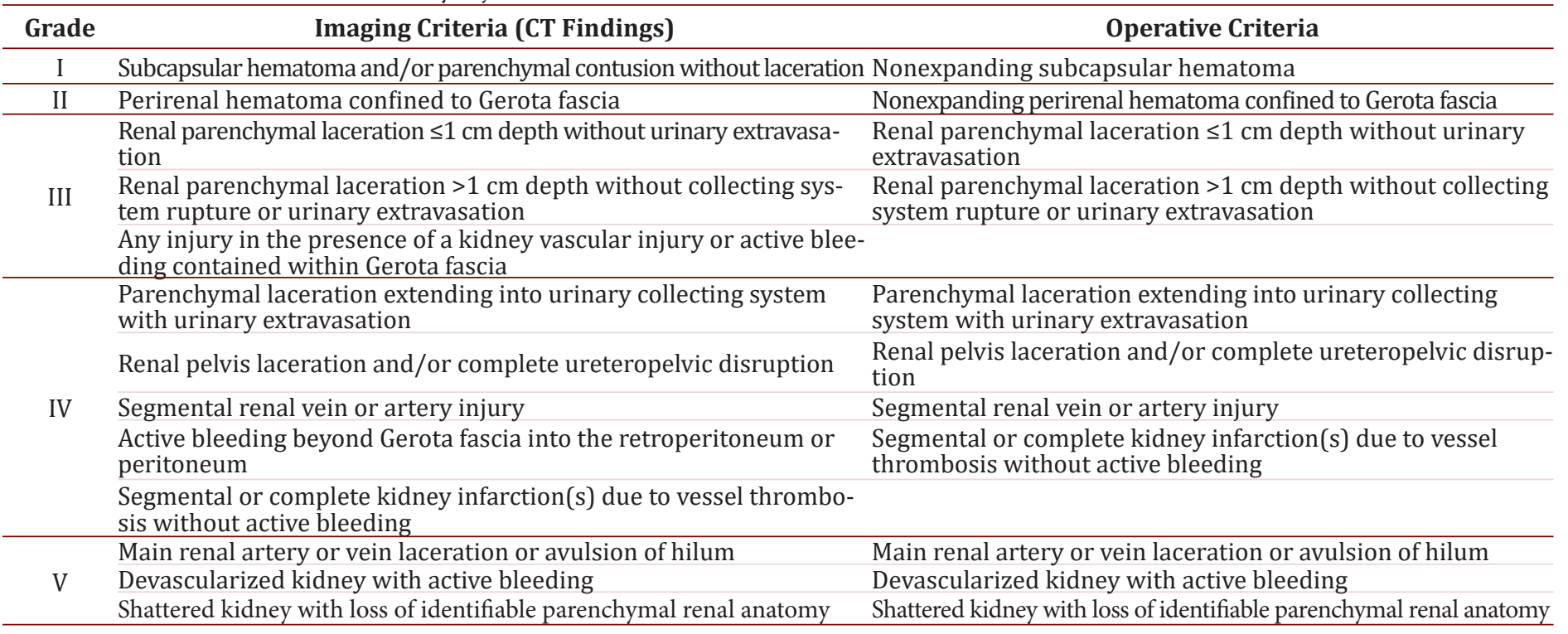

performed with acquisition of arterial, venous and late phases aiming a full visualization of the urinary tract ${ }^{15,24,25}$, which allows to stage the patient and to determine the optimal treatment ${ }^{15}$. Common femoral artery and venous access must be obtained to ensure continuous hemostatic resuscitation, invasive hemodynamic monitoring and, in case of persistent hemodynamic instability, insertion of a Resuscitative Endovascular Balloon Occlusion of the Aorta (REBOA) ${ }^{25}$.

If the patient has a penetrating wound with hemodynamic instability or peritoneal irritation signs, he or she must be immediately transferred to the Operating Room (OR). Kidney, ureter, and bladder injuries must be classified during surgery by means of the American Association for Surgery of Trauma (AAST) score (Tables 1, 2,3 and and.4). The World Society of Emergency Surgery has postulated a classification system for kidney trauma which includes both the kidney anatomic injury and the hemodynamic status of the patient (Table 5) ${ }^{15,26 .}$

Table 2. AAST classification of ureter injury ${ }^{26}$

\begin{tabular}{ccl}
\hline Grade & Type of Injury & \multicolumn{1}{c}{ Description of Injury } \\
\hline I & Hematoma & Contusion or hematoma without devascularization \\
II & Laceration & $<50 \%$ transection \\
III & Laceration & $\geq 50 \%$ transection \\
IV & Laceration & Complete transection with $<2 \mathrm{~cm}$ devascularization \\
V & Laceration & Avulsion with $>2 \mathrm{~cm}$ of devascularization \\
\hline
\end{tabular}

Table 3. AAST classification of bladder injury ${ }^{26}$.

\begin{tabular}{|c|c|c|}
\hline Grade & Type of injury & Description of injury \\
\hline \multirow[t]{2}{*}{ I } & Hematoma & Contusion, intramural hematoma \\
\hline & Laceration & Partial thickness \\
\hline II & Laceration & Extraperitoneal bladder wall laceration $<2 \mathrm{~cm}$ \\
\hline III & Laceration & $\begin{array}{l}\text { Extraperitoneal }(\geq 2 \mathrm{~cm}) \text { or intraperitoneal }(<2 \mathrm{~cm}) \\
\text { bladder wall laceration }\end{array}$ \\
\hline IV & Laceration & Intraperitoneal bladder wall laceration $\geq 2 \mathrm{~cm}$ \\
\hline $\mathrm{V}$ & Laceration & $\begin{array}{l}\text { Intraperitoneal or extraperitoneal bladder wall } \\
\text { laceration extending into the bladder neck or } \\
\text { ureteral orifice (trigone) }\end{array}$ \\
\hline
\end{tabular}


Table 4. AAST classification of urethra injury ${ }^{26}$.

\begin{tabular}{cll}
\hline Grade & Type of Injury & Description of Injury \\
\hline I & Contusion & Blood at urethral meatus; retrography normal \\
II & Stretch injury & Elongation of urethra without extravasation on urethrography \\
III & Partial disruption & Extravasation of urethrography contrast at injury site with visualization in the bladder \\
IV & Complete disruption & Extravasation of urethrography contrast at injury site without visualization in the bladder, $<2$ cm of \\
V & Complete disruption & Complete transaction with $>2 \mathrm{~cm}$ urethral separation, or extension into the prostate or vagina. \\
\hline
\end{tabular}

Table 5. WSES classification of kidney trauma

\begin{tabular}{|c|c|c|c|}
\hline WSES Grade & & & Hemodynamic Status \\
\hline Moderate & WSES Grade II & \multirow{4}{*}{$\begin{array}{l}\text { III or segmental vascular injuries } \\
\text { III or segmental vascular injuries } \\
\text { IV-V or any grade parenchymal lesion with main } \\
\text { vessels dissection / occlusion } \\
\text { Any }\end{array}$} & Stable \\
\hline Moderate & WSES Grade II & & Stable \\
\hline \multirow[t]{2}{*}{ Severe } & WSES Grade III & & Stable \\
\hline & WSES Grade IV & & \\
\hline
\end{tabular}

\section{Surgical approach}

During the exploratory laparotomy, the trauma surgeon should assess and seek to control all sources of ongoing surgical bleeding and bowel contamination. If the patient remains with hemodynamic instability with a sustained SBP $(70 \mathrm{~mm} \mathrm{Hg}$, in spite of an optimal damage control resuscitation, the placement of a REBOA in zone 1 should be considered as an adjunct for hemostatic resuscitation ${ }^{27}$. Later, the surgeon should assess the possible injuries of abdominal organs. If a retroperitoneal hematoma is found, then a renal or urinary tract injury must be suspected. The Trauma and Acute Care Surgery Group (CTE) from Cali, Colombia, proposes the following management approach for renal and urinary tract injury (Figure 1):

- $\quad$ Peri-renal Hematoma AAST Grade II (Figure 2): If a medium-size and non-expanding hematoma is visualized and the patient is hemodynamically stable, the management must be conservative. Our recommendation is to leave the kidney untouched and unexplored, to complete damage control in other organs and to transfer the patient to the Intensive Care Unit (ICU). Once the patient is hemodynamically stable, a Whole-Body CT (WBCT) is recommended to evaluate the renal injury, to decide definitive management and to assess the need for urology consultation.

- Peri-renal large hematoma, non-expanding, and without active bleeding AAST Grade II- III (Figure 3): If a large peri-renal hematoma is found, but it is non-expanding and has non-active bleeding, then peri-renal packing is recommended. Renal exploration must be avoided at all causes and it is not recommended to open Gerota's fascia. Remember: "touched kidney, removed kidney". The surgeon should complete damage control surgery leaving the abdomen opened and placing a negative pressure system. Continuous hemostatic resuscitation and immediate CT should follow. If CT shows any evidence of renal arterial bleeding, a selective angioembolization of the affected branch or the principal renal artery (as a last resource) should be performed (Figure 4). If there is any evidence of injury to the renal pelvis or the ureters, the patient should receive an emergency urology consult to decide whether a double J catheter should be placed and to plan definitive management.

- Massive peri-renal hematoma, expanding with or without active bleeding AAST Grade IV-V (Figure 5): The suspicion of an AAST grade IV-V renal injury with involvement of the pyelocaliceal system or urinary extravasation makes the kidney surgical exploration mandatory. It is recommended to access the renal hilum through a lateral incision, performing a left or right coloparietal lift. Gerota's fascia is opened through its lateral portion. If there is a possibility of preserving the functional kidney parenchyma, the 


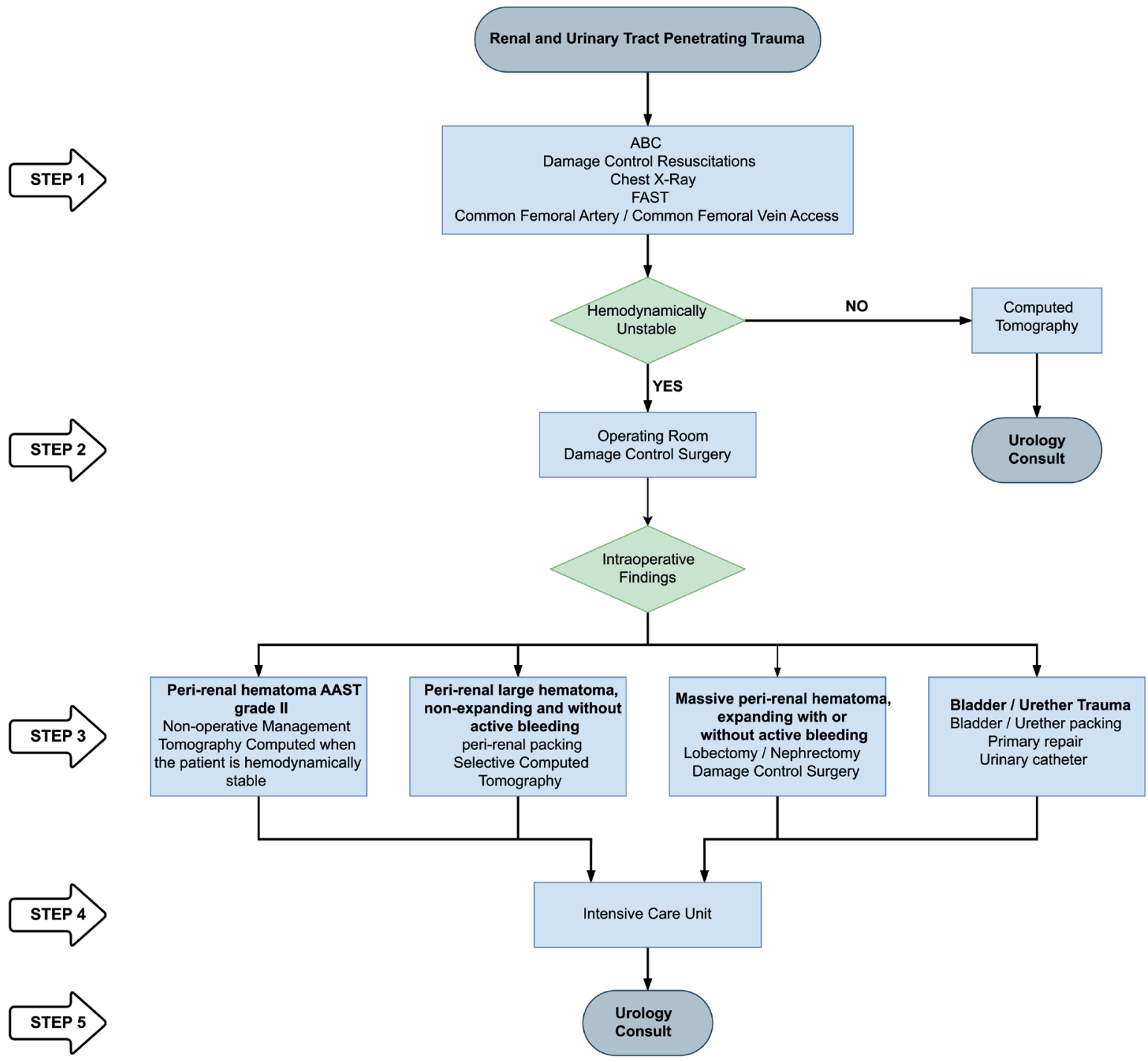

Figure 1. Algorithm for the management of renal and urinary tract penetrating trauma

surgeon can perform a lobectomy of the affected area or a nephrorrhaphy with a matters suture using monofilament and adding a local hemostatic (oxidized regenerated cellulose, fibrin sealant, among other). Then, the renal fossa should be packed and damage control surgery should be completed. The abdomen must be left opened with a negative pressure system and the patient must be transferred to the ICU. In 24-48 hours, the patient must be re-intervened to re-assess the abdominal cavity and to decide the definitive management with the urologist.

- If there is renal parenchyma destruction, renal artery or vein disruption, with injury of the pyelocaliceal system and urinary extravasation, it is impossible to save the kidney and a nephrectomy must be performed. The renal artery and vein should be double ligated with silk 1.0 but, if not possible, the whole vascular package can be ligated. Then, the nephrectomy is performed ligating the ureter as low as possible. Once done, the renal fossa is packed and damaged control surgery is completed, leaving the abdomen open with a negative pressure system. Finally, the patient is transferred to the ICU to complete the hemostatic resuscitation. In 24-48 hours, he or she is re-intervened to re-assess the abdominal cavity, unpack the renal fossa and to continue the management of other injuries. 

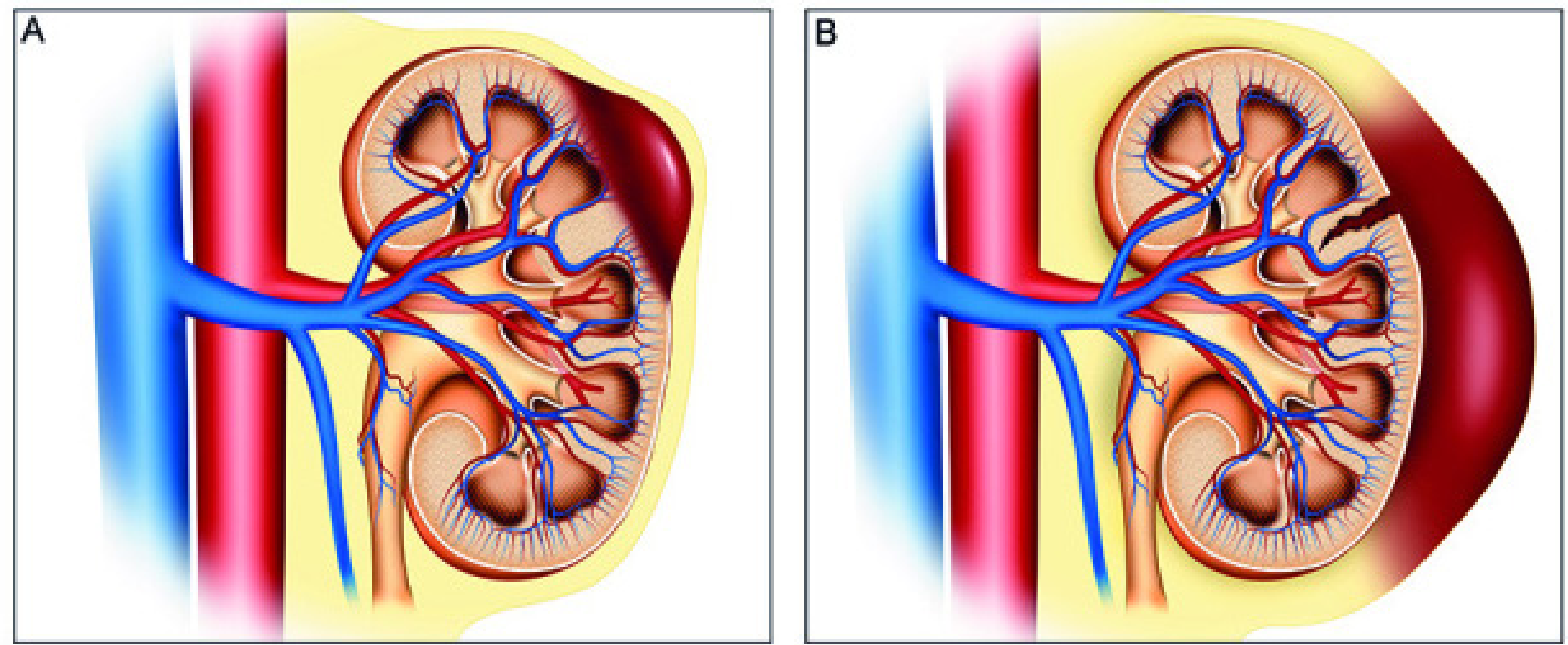

Figure 2. Renal trauma with a medium-size peri-renal hematoma A. AAST Grade I; B AAST Grade II. If a medium-size and non-expanding hematoma is visualized and the patient is hemodynamically stable, the management must be conservative. Leave the kidney untouched and unexplored, complete damage control in other organs and transfer the patient to the ICU. Once the patient is hemodynamically stable, a WBCT is recommended to evaluate the renal injury, to decide definitive management and to assess the need for urology consultation.

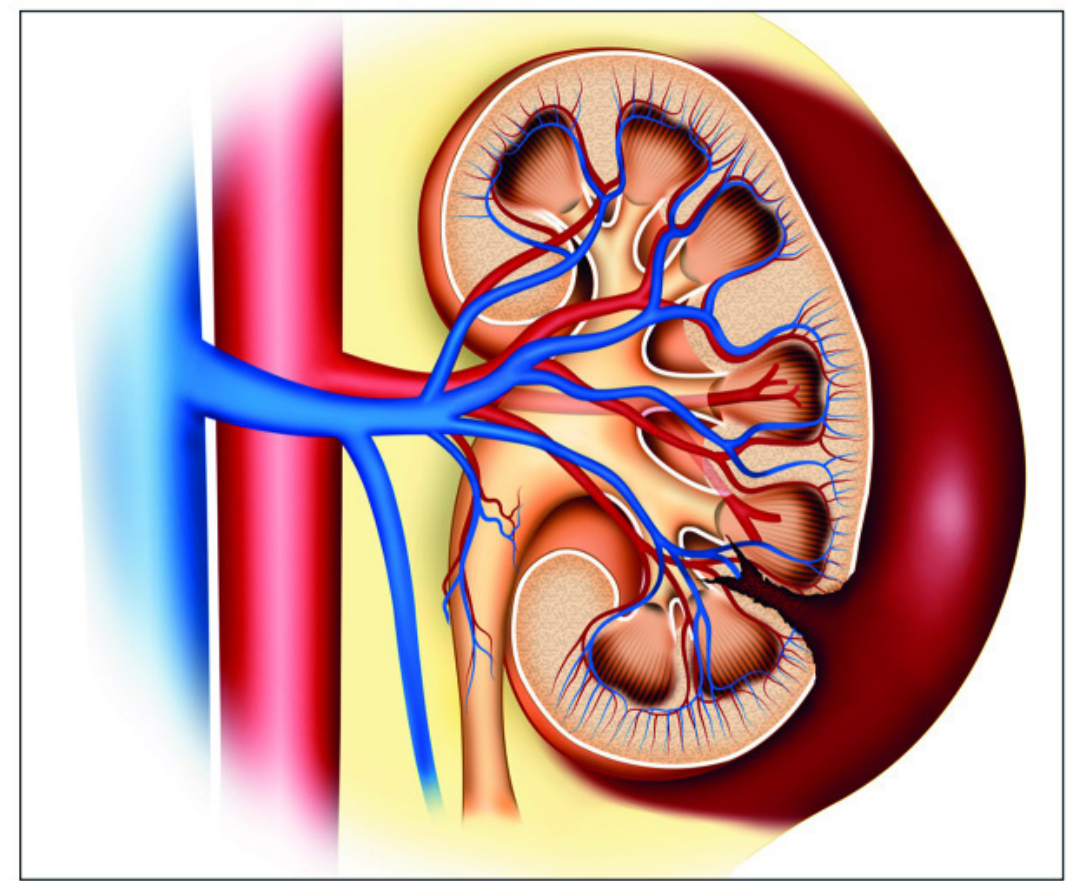

Figure 3. Renal trauma with a large and non-expending peri-renal hematoma, and no active bleeding: c. If a large and non-expanding peri-renal hematoma, with no active bleeding is found, peri-renal packing is recommended. Renal exploration must be avoided at all causes and it is not recommended to open Gerota's fascia. The surgeon should complete damage control surgery leaving the abdomen opened and placing a negative pressure system. Continuous hemostatic resuscitation and immediate WBCT should follow. 

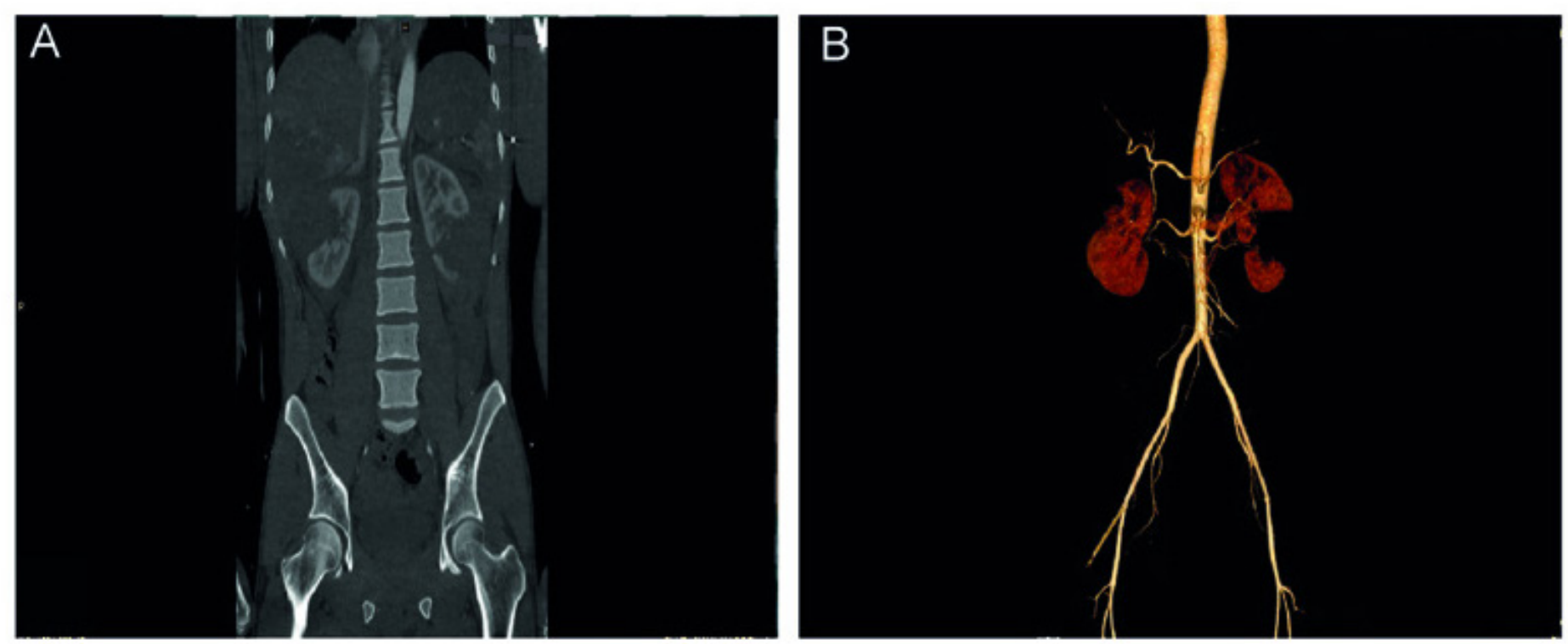

Figure 4. Double-contrasted CT with angiographic reconstruction, showing renal trauma. A. Left kidney AAST grade III injury, with no signs suggesting involvement of the pyelocaliceal system. B. Angiographic reconstruction showing involvement of the middle and distal third, with no evidence of major vascular injury.
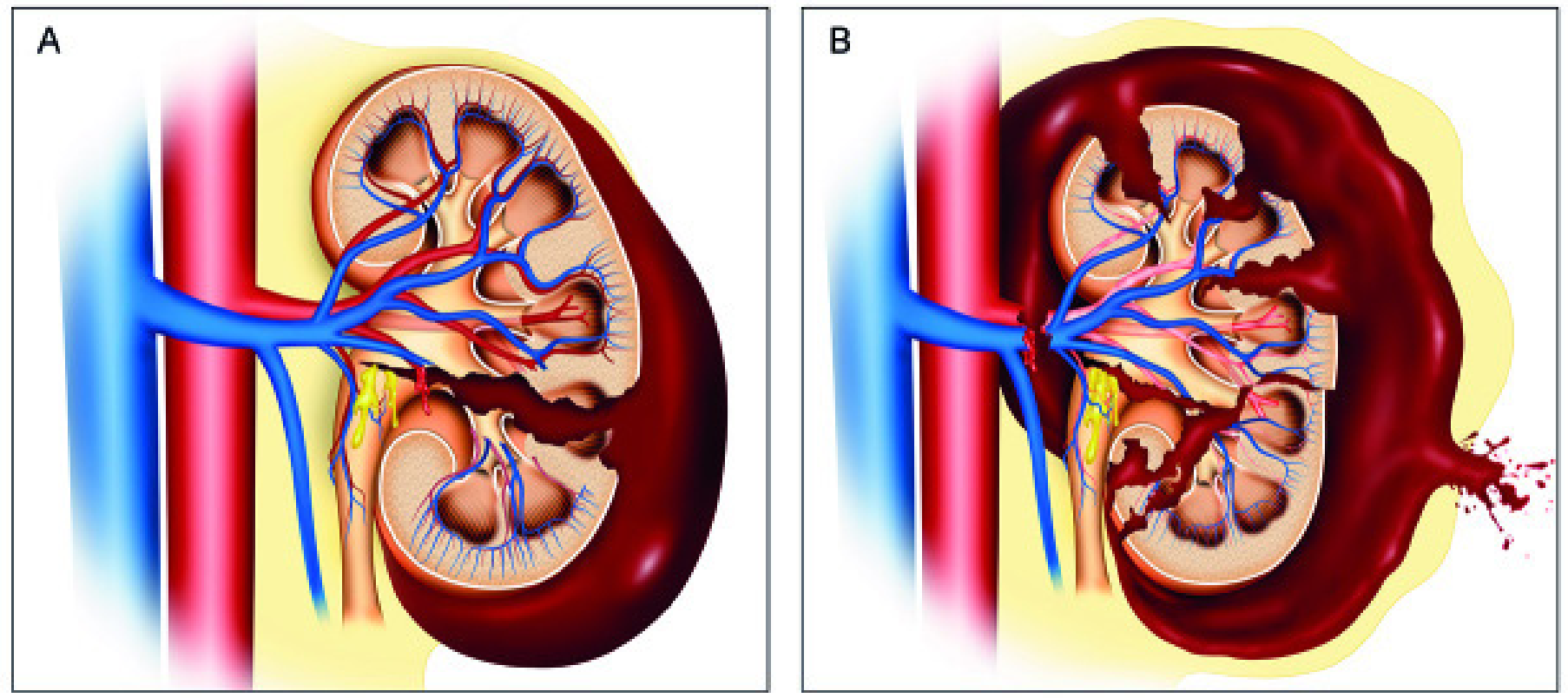

Figure 5. Renal trauma with massive peri-renal hematoma, expanding and with active bleeding: A: AAST grade IV injury; B: AAST grade V injury. Surgical exploration is mandatory. It is recommended to access the renal hilum through a lateral incision, performing a left or right coloparietal lift. Gerota's fascia is opened through its lateral portion. If there is a possibility of preserving the functional kidney parenchyma, perform a lobectomy of the affected area or a nephrorrhaphy with a matters suture using monofilament and adding a local hemostatic (oxidized regenerated cellulose, fibrin sealant, among other). If there is renal parenchyma destruction, renal artery or vein disruption, with injury of the pyelocaliceal system and urinary extravasation, it is impossible to save the kidney and a nephrectomy must be performed. Then, the renal fossa should be packed, and damage control surgery should be completed. 
- Damage control of the ureter: Renal injuries are frequently related to ureteral injuries. However, in the acute management, the ureter is not an important source of bleeding. Hence, measures like the retroperitoneum packing are usually enough. During damage control surgery, a systematic search of the ureter within a hematoma is not recommended because it can consume valuable time. In addition, when a wide and inappropriate dissection is performed, there is a risk of devascularization of the ureteral wall. However, if it is found expeditious, a ligature with silk 2-0 can be

- done as distal as possible. The abdomen must be left opened with a negative pressure system and the patient is transferred to the ICU for physiological resuscitation. When the patient is hemodynamically stable, a contrasted CT must be performed to assess and stage the damage. Finally, the urologist must be consulted to decide the placement of a double J catheter or a percutaneous nephrostomy, and define the possible definitive management.

- Damage control of the bladder: Bladder injury or urinary extravasation does not increase risk of death during the first 24 hours of management. If possible, the bladder must be sutured in a single plane with a continue suture and absorbable 2-0 along with packing of the zone and insertion of a foley catheter. However, if there is destruction of the bladder in a patient with hemodynamic instability, other injuries must be prioritized, and the pelvis should be packed with the insertion of a foley catheter. Patient must be transferred to the ICU to continue hemostatic resuscitation and then the urologist must decide the definitive management.

All patients with renal and urinary tract trauma must have a urinary catheter and receive an almost immediate evaluation by the urologist.

\section{Complications}

After a renal trauma, the complications rate could occur in $3-33 \%$ of the cases ${ }^{28}$. The most frequent early complications are bleeding, peri nephritic abscess, hypertension, and urinoma ${ }^{28}$. Late complications include bleeding, urolithiasis, hydronephrosis, chronic pyelonephritis, arteriovenous fistula, and kidney failure ${ }^{28}$. Starnes et al. evaluated the frequency of complications in 889 patients according to their type of management. They found that $1.3 \%$ had kidney failure, and this was more common in patients who underwent a nephrectomy than in those who did not $(4.6 \%$ vs $0.6 \%, \mathrm{p}<0.001)$. On the other hand, $5.2 \%$ of the patients had other complications, the most common was urinary tract infection (2.3\%), followed by urinary extravasation (1.2\%) and persistent bleeding $(1.2 \%)^{29}$.

\section{Discussion}

Patients with severe renal trauma with AAST Grade IV and V injuries have a greater chance of requiring a nephrectomy ${ }^{30}$. Likewise, patients with penetrating trauma have higher risk of requiring a nephrectomy than patients with blunt trauma ${ }^{31}$. Patients with hemodynamic stability or AAST Grade I-II-III injuries should receive non-surgical management, through imaging evaluation and, if necessary, endovascular management of the bleeding sources. Conservative management has allowed to decrease the rate of nephrectomies, hospital stay, and complications ${ }^{15}$. Even though penetrating trauma has a higher risk of nephrectomy, it is not an absolute indication for surgical management. Navsaria et al. performed a prospective study which assessed patients with renal trauma due to gunshot wounds, without indication for emergency laparotomy. The non-operative management was successful in $90 \%$ of the patients, without requiring surgical exploration of the abdominal cavity ${ }^{32}$. Schellenger and Demetriades et al. reported 459 patients with renal trauma caused by a gunshot wound, of which, the majority had AAST Grade I-II-III injuries. These patients were treated with non-operative management and when compared with patients who underwent surgical management, they had shorter hospital stay, lower frequency of complications, and lower nephrectomy requirement ${ }^{33}$. Hotaling et al. ${ }^{31}$, conducted a retrospective analysis of the National Trauma Data Bank including 
around 9,000 patients with renal trauma, of which, 78\% presented AAST grade IV-V injuries. Eighty three percent of AAST grade V renal trauma were treated through a non-operative approach via an endovascular or expectant manage, without undergoing nephrectomy, in spite of requiring a second surgical intervention in $88 \%$ of the cases.

A non-expanding perirenal hematoma with active bleeding is a hot topic regarding the indication for surgical exploration, even in penetrating trauma patients. In 1998, Velmahos and Demetriades et al. ${ }^{34}$, reported a case series of patients with renal trauma due to gunshot wounds, of which, $40 \%$ did not require renal surgical exploration. They also mention that a hilum injury and ongoing bleeding are indicators for surgical exploration, on the contrary, a stable perirenal hematoma does not indicate a surgical approach.

Clinical observation of the peri-renal hematoma without surgical exploration has been used since the pre-CT era. In 1985, Cass et al. ${ }^{35}$, described a case series of 158 patients with renal trauma. They found that the size of the hematoma was directly associated with the type of injury. If the hematoma was small and non-expanding, it was due to a renal contusion and renal artery thrombosis. While bigger and expanding hematomas, or with active bleeding, might be due to major lacerations, kidney rupture or injury of the renal pelvis with major lacerations of the vascular structures. The recommendation is that, if the patient could not be evaluated with a CT, the hematoma size can be a criterion to decide the pertinence of surgical exploration. In addition, it can also be a criterion to decide of whether to perform damage control measures and posterior radiological evaluation, or direct surgical exploration of the kidney ${ }^{15,36}$.

Most of the injuries of ureters, bladder, urethra, and external genitalia require non-surgical management or minimally invasive management. In cases of requiring surgery, the stages of repair must be planned after the damage control surgery. The joint work of the trauma and acute care surgeon, the intensive care physician, the urologist, and the endovascular specialist is the best way to approach the patients with urinary tract trauma, considering that they often require different and combined treatment strategies.

\section{Conclusion}

When treating a patient with hemodynamic instability and renal trauma, the surgeon has to make decision during initial laparotomy for which there are not clear guidelines. It is recommended to adopt the believe that the more conservative the surgeon, better for the kidney. Surgical exploration should be performed only if the injury requires it and the nephrectomy should be performed only if it is impossible to save the kidney. Bladder and ureter trauma do not carry a high risk of death, so it is recommended to defer the repair or to perform surgical maneuvers that do not interfere with the damage control surgery and allow an early transfer to the ICU for hemodynamic resuscitation.

\section{References}

1. Viola TA. Closed Kidney Injury. Clin Sports Med. 2013;32:219-27. Doi: 10.1016/j.csm.2012.12.002.

2. Sujenthiran A, Elshout PJ, Veskimae E, MacLennan S, Yuan Y, Serafetinidis E, et al. Is Nonoperative Management the Best First-line Option for High-grade Renal trauma? A Systematic Review. Eur Urol Focus. 2019;5:290-300. Doi: 10.1016/j.euf.2017.04.011.

3. Veeratterapillay R, Fuge O, Haslam P, Harding C, Thorpe A. Renal trauma. J Clin Urol. 2017;10:379-90. Doi: 10.1177/2051415817691642.

4. Gross JA, Lehnert BE, Linnau KF, Voelzke BB, Sandstrom CK. Imaging of Urinary System Trauma. Radiol Clin North Am. 2015;53:773-88. Doi: 10.1016/j.rcl.2015.02.005. 
5. Bittenbinder EN, Reed AB. Advances in renal intervention for trauma. Semin Vasc Surg. 2013;26:165-9. Doi: 10.1053/j.semvascsurg.2014.06.012.

6. Heller MT, Schnor N. MDCT of renal trauma: Correlation to AAST organ injury scale. Clin Imaging. 2014;38:410-7. Doi: 10.1016/j.clinimag.2014.02.001.

7. Shewakramani S, Reed KC. Genitourinary Trauma. Emerg Med Clin North Am. 2011;29:501-18. Doi: 10.1016/j.emc.2011.04.009.

8. Keihani S, Xu Y, Presson AP, Hotaling JM, Nirula R, Piotrowski J, et al. Contemporary management of highgrade renal trauma: Results from the American Association for the Surgery of Trauma Genitourinary Trauma study. J Trauma Acute Care Surg. 2018;84:418-25. Doi: 10.1097/TA.0000000000001796.

9. Javanmard B, Fallah-Karkan M, Razzaghi M, Ansari Djafari A, Ghiasy S, Lotfi B, et al. Characteristics of Traumatic Urogenital Injuries in Emergency Department; a 10-year Cross-sectional Study. Arch Acad Emerg Med. 2019;7:e63.

10. Knudson MM, Harrison PB, Hoyt DB, Shatz D V., Zietlow SP, Bergstein JM, et al. Outcome after major renovascular injuries: A western trauma association multicenter report. J Trauma. 2000;49:1116-22. Doi: 10.1097/00005373-200012000-00023.

11. Kansas BT, Eddy MJ, Mydlo JH, Uzzo RG. Incidence and management of penetrating renal trauma in patients with multiorgan injury: extended experience at an inner city trauma center. J Urol. 2004;172:1355-60. Doi: 10.1097/01.ju.0000138532.40285.44.

12. Mingoli A, Torre M La, Migliori E, Cirillo B, Zambon M, Sapienza P, et al. Operative and nonoperative management for renal trauma: Comparison of outcomes. A systematic review and meta-analysis. Ther Clin Risk Manag. 2017;13:1127-38. Doi: 10.2147/TCRM.S139194.

13. Kong JPL, Bultitude MF, Royce P, Gruen RL, Cato A, Corcoran NM. Lower urinary tract injuries following blunt trauma: a review of contemporary management. Rev Urol. 2011;13:119-30. Doi: 10.3909/riu0521.

14. Pereira BMT, Ogilvie MP, Gomez-Rodriguez JC, Ryan ML, Peña D, Marttos AC, et al. A review of ureteral injuries after external trauma. Scand J Trauma Resusc Emerg Med. 2010;18:1-11. Doi: 10.1186/1757-7241-18-6.

15. Coccolini F, Moore EE, Kluger Y, Biffl W, Leppaniemi A, Matsumura Y, et al. Kidney and uro-trauma: WSESAAST guidelines. World J Emerg Surg. 2019;14:1-25. Doi: 10.1186/s13017-019-0274-x.

16. Santucci RA, Bartley JM. Urologic trauma guidelines: A 21 st century update. Nat Rev Urol. 2010;7:510-9. Doi: 10.1038/nrurol.2010.119.

17. Benz D, Balogh ZJ. Damage control surgery: Current state and future directions. Curr Opin Crit Care. 2017;23:491-7. Doi: 10.1097/MCC.0000000000000465.

18. Kalkwarf KJ, Holcomb JB. Damage control resuscitation. Surg Crit Care Ther A Clin Oriented Pract Approach. 2018;7:337-45. Doi: 10.1007/978-3-319-71712-8_32.

19. Becker A, Lin G, McKenney MG, Marttos A, Schulman Cl. Is the FAST exam reliable in severely injured patients? Injury. 2010;41:479-83. Doi: 10.1016/j.injury.2009.10.054.

20. Kirkpatrick AW, Sirois M, Ball CG, Laupland KB, Goldstein L, Hameed M, et al. The hand-held ultrasound examination for penetrating abdominal trauma. Am J Surg. 2004;187:660-5. Doi: 10.1016/j. amjsurg.2004.02.003.

21. Kirkpatrick AW, Sirois M, Laupland KB, Liu D, Rowan K, Ball CG, et al. Hand-held thoracic sonography for detecting post-traumatic pneumothoraces: The extended focused assessment with sonography for trauma (EFAST). J Trauma. 2004;57:288-95. Doi: 10.1097/01.TA.0000133565.88871.E4. 
22. Jalli R, Kamalzadeh N, Lotfi M, Farahangiz S, Salehipour M. Accuracy of sonography in detection of renal injuries caused by blunt abdominal trauma: a prospective study. Ulus Travma ve Acil Cerrahi Derg. 2009;15:23-7.

23. Bryk DJ, Zhao LC. Guideline of guidelines: A review of urological trauma guidelines. BJU Int. 2016;117:22634. Doi: $10.1111 /$ bju. 13040.

24. Morey AF, Brandes S, Dugi DD, Armstrong JH, Breyer BN, Broghammer JA, et al. Urotrauma: AUA guideline. J Urol. 2014;192:327-35. Doi: 10.1016/j.juro.2014.05.004.

25. Manzano Nunez R, Naranjo MP, Foianini E, Ferrada P, Rincon E, García-Perdomo HA, et al. A metaanalysis of resuscitative endovascular balloon occlusion of the aorta (REBOA) or open aortic cross-clamping by resuscitative thoracotomy in non-compressible torso hemorrhage patients. World J Emerg Surg. 2017;12:30. Doi: 10.1186/s13017-017-0142-5.

26. Moore EE, Cogbill TH, Jurkovich GJ, McAninch JW, Champion HR, Gennarelli TA, et al. Organ injury scaling. III: Chest wall, abdominal vascular, ureter, bladder, and urethra. J Trauma. 1992;33:337-9. Doi: 10.1097/00005373-199209000-00001

27. Osborn LA, Brenner ML, Prater SJ, Moore LJ. Resuscitative endovascular balloon occlusion of the aorta: Current evidence. Open Access Emerg Med. 2019;11:29-38. Doi: 10.2147/OAEM.S166087.

28. Al-Qudah HS, Santucci RA. Complications of renal trauma. Urol Clin North Am. 2006;33:41-53. Doi: 10.1016/j.ucl.2005.10.005.

29. Starnes M, Demetriades D, Hadjizacharia P, Inaba K, Best C, Chan L. Complications following renal trauma. Arch Surg. 2010;145:377-81. Doi: 10.1001/archsurg.2010.30.

30. Wright JL, Nathens AB, Rivara FP, Wessells H. Renal and extrarenal predictors of nephrectomy from the National Trauma Data Bank. J Urol. 2006;175:970-5. Doi: 10.1016/S0022-5347(05)00347-2.

31. Hotaling JM, Sorensen MD, Smith TG, Rivara FP, Wessells H, Voelzke BB. Analysis of diagnostic angiography and angioembolization in the acute management of renal trauma using a national data set. J Urol. 2011;185:1316-20. Doi: 10.1016/j.juro.2010.12.003.

32. Navsaria PH, Nicol AJ. Selective nonoperative management of kidney gunshot injuries. World J Surg. 2009;33:553-7. Doi: 10.1007/s00268-008-9888-y.

33. Schellenberg M, Benjamin E, Piccinini A, Inaba K, Demetriades D. Selective nonoperative management of renal gunshot wounds. J Trauma Acute Care Surg. 2019;87:1301-7. Doi: 10.1097/TA.0000000000002475.

34. Velmahos GC, Demetriades D, Cornwell EE, Belzberg H, Murray J, Asensio J, et al. Selective management of renal gunshot wounds. Br J Surg. 1998;85:1121-4. Doi: 10.1046/j.1365-2168.1998.00798.x

35. Cass AS, Luxenberg M, Gleich P, Hollander J, Smith C. Management of perirenal hematoma found during laparotomy in patient with multiple injuries. Urology. 1985;26:546-9. Doi: 10.1016/0090-4295(85)90357-7.

36. Keihani S, Rogers DM, Putbrese BE, Moses RA, Zhang C, Presson AP, et al. A nomogram predicting the need for bleeding interventions after high-grade renal trauma: Results from the American Association for the Surgery of Trauma Multi-institutional Genito-Urinary Trauma Study (MiGUTS). J Trauma Acute Care Surg. 2019;86:774-82. Doi: 10.1097/TA.0000000000002222. 